\title{
XLII. On the radioactivity of metals generally
}

\section{J.C. McLennan \& E.F. Burton}

To cite this article: J.C. McLennan \& E.F. Burton (1903) XLII. On the radioactivity of metals generally, Philosophical Magazine Series 6, 6:33, 343-350, DOI: 10.1080/14786440309463025

To link to this article: http://dx.doi.org/10.1080/14786440309463025

册 Published online: 15 Apr 2009.

Submit your article to this journal $\pi$

Џll Article views: 2

Q View related articles ¿

Citing articles: 3 View citing articles $\square$ 
after Gauss, begins his later paper (Leipziger Berichte, vol. vii. (1855)) by stating that he had recently become convinced that the chief properties of a system of lenses can be deduced by a purely geometric method much more easily than by continued fractions. But in the actual working out of his method, he uses continued fractions after all. To mention more recent writers, Herman in his lately published Treatise bases his treatment on the well-known optical theorem of Cotes; but the symbolic expressions involved in that theorem seem quite as complicated as continued fractions. And Chrystal, in his paper in the Proceedings of the Edinburgh Mathematical Society, vol. xiv. (1895), gives a very concise and complete summary of the theory, avoiding intermediate calculations, but purely algebraic in its character.

I may mention that I had worked out the foregoing method in all its main features and in its chief details when my acquaintance with the theory of the cardinal points was derived solely from the treatises of Healb and of Herman, and the paper by Chrystal. On looking up the literature bearing on the subject that was accessible to me, I found that, so far as details are concerned, very much had been anticipated by previous writers, amongst whom I might specially mention Bravais (Ann. de Chimie et de Physique, 3rd ser. vol. xxxiii. (1851)) who points out the existence of what I have called the vertex for a point; and A. Martin (ibid. 4th ser. vol. x. (1867)) who develops the ideas of Gauss, Bravais, Verdet, and Listing, and who points out the existence of what I have called the base-plane for an axial point (plan refracteur); as well as Möbius and Clerk Maxwell, already mentioned.

But I did not find any anticipation of my fundamental idea of method; and the very considerable simplification I have been able to introduce into the geometric treatment of the subject seems to me to justify publication.

XLII. On the Radioactivity of Metals generally. By J. C. McLennan aned E. F. Bunton, University of Toronto*.

\section{Introduction.}

$I^{\mathrm{I}}$ $\mathrm{N}$ a former paper by the authors + on the conductivity of a mass of ordinary air confined within a large metallic receiver, it was shown that about 37 per cent. of ibe conductivity was due to an exceedingly penetrating radiation

* Communicated by the Authors: read before the Royal Society of Canada, May 18, 1903.

† Phys. Review, vol. xvi. No. 3, p. 184 (1903). 
which, traversing the air in the room, passed through the walls of the receiver. It was also shown that the conductivity of fresh atmospheric air, after being confined in a metallic cylinder, rapidly fell to a minimum value, that a gradual rise then took place, and that a steady state was reached after some hours.

On account of the known decay of the constituent in atmospheric air responsible for excited radioactivity, the fall in the initial conductivity was attributed to its presence in the cylinder, and the subsequent rise to an emanation of a similar character given off by the walls of the containing vessel ; the steady state representing a condition of equilibrium where the rate of decay of this emanation was equal to the rate at which it was produced.

It was also pointed out that the limiting value of the conductivity thus reached varied with the metals forming the walls of the receiver. In experiments with lead, tin, and zinc the conductivity was highest with lead and lowest with zinc. In view of these results and on account of the known complex character of the radiations from such highly radioactive substances as radium and thorium, a series of experiments was made to investigate still further the radioactivity of ordinary metals.

As a result of these experiments we find that when a cylinder of any metal is inclosed within a second of the same material, insulated from it, and surrounded by air or other gases, it gradually acquires a negative charge, and after a short time reaches a state of equilibrium at a definite potential below that of the inclosing cylinder.

So far the experiments made indicate that the negative charge acquired by the cylinder results from a process in which an excess of positively charged corpuscles is expelled from its surface. This process is probably identical with the $\alpha$ radiation observed by Rutherford ${ }^{*}$ and others in the highly radioactive substances radium, thorium, and uranium, and experiments are now being made by the writers to determine its relation to the effect observed by Guthrie + , and developed by Elster and Geitel $\ddagger$, J.J. Thomson $\S$, Richardson \|, Strutt 9, and others, that a metal-platinum, for example,when heated to a dull red, will discharge a negatively charged body placed near it, but not one positively charged.

* Phil. Mag. Feb. 1903, p. 177.

+ Phil. Mag. [4] vol. xlvi. p. 257 (1873).

† Wied. Ann. vol. xxxviii. p. 27 (1889).

Phil. Mag. vol. xliv. p. 203 (1897).

il Proc. Camb. Phil. Soc. vol. xi. p. 286.

I Phil. Mag. [6] rol. iv. p. 98 (1902). 


\section{Experiments.-Metal Effect.}

In these experiments cylinders of aluminium, zinc, lead, tin, and copper were used, the outer ones being $120 \mathrm{cms}$. in length and $24 \mathrm{cms}$. in diameter, and the inner $110 \mathrm{cms}$. in length and 19 cms. in diameter. The measurements were made with a quadrant electrometer whose sensitiveness was such as to give a deflexion of $1000 \mathrm{mms}$. on a scale situated at 1 metre from the needle for a potential of 1 volt.

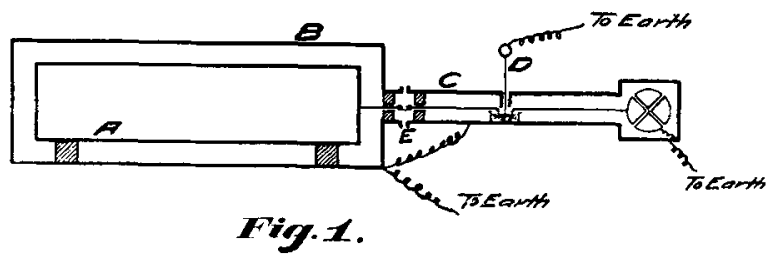

The apparatus and its connexions are shown in fig. 1, where $A$ and $B$ represent the cylinders of the metal examined. The wire which led from the inner cylinder to the electrometer was of brass, and was surrounded by a tabe of the same metal to screen off induction effects. This tube, as well as the outer cylinder $\mathrm{B}$ and the metallic screen over the electrometer, was kept joined to earth during an experiment. The inner cylinder and the free quadrants were earihed by means of the brass rod $\mathrm{D}$, which carried a platinum tip and made contact with a small platinum plate attached to the connecting wire as shown in the figure. The tube was provided with a small opening so arranged that the withdrawal of the rod D did not affect the capacity of the system. Plugs and supports of paraffin-wax provided insulation for the apparatus.

In making a measurement the connecting rod $\mathrm{D}$ was withdrawn and the apparatus left intact. The inner cylinder $B$ and the free quadrants then slowly acquired a negative charge which finally reached a limiting value. The value varied with the metal used in the construction of the cylinders $A$ and $B$, but did not vary with samples of the same metal obtained from different sources. It was also the same whether the needle of the electrometer was positively or negatively charged. With lead, tin, and copper the limiting value was reached in about one hour, but with aluminium and zinc not before four or five bours had elapsed.

Readings for pairs of cylinders of these metals at the 
temperature of the room are set forth in fig. 2, where curves are drawn with the time expressed in hours for abscissæ, and the

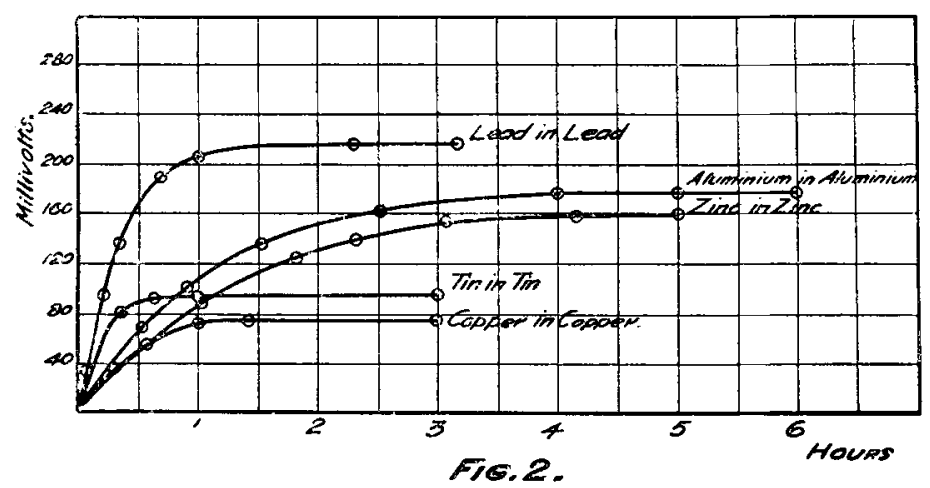

negative potential attained by the inner cylinder expressed in millivolts for ordinates. The limiting values for the different metals are as follows :-

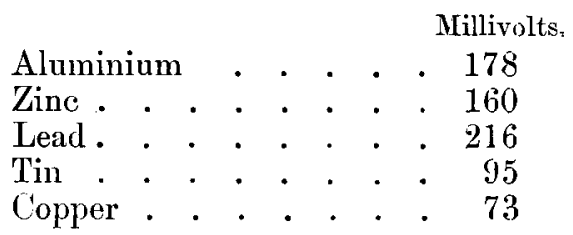

In experimenting with lead cylinders the pressure of the air in $B$ was reduced from 750 mms. to $20 \mathrm{mms}$. of mercury, and a slight drop in the limiting potential of about 3 or 4 per cent. was observed.

Measurements were also made with different gases at atmospheric pressure between these cylinders, and it was found that the limiting potential slightly increased with the density of the gas used. A set of readings taken with bydrogen, air, oxygen, and carbon dioxide is as follows :-

$$
\begin{aligned}
& \text { Millivolts. } \\
& \text { Hydrogen . . . . . } 205 \\
& \text { Air . . . . . . . } 216 \\
& \text { Oxygen . . . . . . . } 220 \\
& \text { Carbon dioxide . . . . } 233
\end{aligned}
$$

Experiments were also made with lead by varying the diameter of the inner cylinder. With cylinders 19, 13, and $4 \mathrm{cms}$. in diameter respectively, no difference was observed in the limiting potential; but the time required to 
reach it slightly increased with the use of cylinders of smaller diameter.

The experiments were also varied by placing the lead cylinders in a tank filled with water, the surrounding layer of water having a thickness of $13 \mathrm{cms}$. Under these conditions the limiting potential was found to be unchanged.

It was also observed that this metal effect was produced when Röntgen and Becquerel rays were allowed to traverse the cylinders. With these radiations, however, the limiting negative potentials were reached in the course of a few seconds and varied but little from the values obtained for the different metals under ordinary conditions.

A small quantity of radium chloride of activity 1000 confined in a glass phial was used as the source of Becquerel rays, and was placed, in the experiment, on a support close to the outside of the cylinder B. The effect was also produced with a quantity of uranium oxide placed near the cylinder, but a much longer time was required than with the radium to reach the steady state.

The following are the values of the limiting negative potentials obtained under the different conditions.

\begin{tabular}{|c|c|c|c|}
\hline \multirow{2}{*}{ Metal. } & \multicolumn{3}{|c|}{ Negative Potential in Millivolts. } \\
\hline & $\begin{array}{c}\text { Natural } \\
\text { Radiation. }\end{array}$ & Röntgen Rays. & Beequerel Rays. \\
\hline Alumiuium ...... & 179 & 179 & 179 \\
\hline Zine ... & 160 & 176 & 180 \\
\hline Lead ............... & 216 & 175 & 201 \\
\hline $\operatorname{Tin} . . . \ldots \ldots \ldots \ldots$ & 95 & 98 & 100 \\
\hline Copper ............ & 73 & 72 & 69 \\
\hline
\end{tabular}

Volta Effect.

It is evident that with cylinders of different metals the arrangement shown in fig. 1 afforded a means of exhibiting the Volta effect, and of approximating to a measure of the contact differences of potential for a series of metals.

With the rod $D$ in position a difference of potential would exist between the cylinders $A$ and $B$. Its withdrawal would be followed by a gradual equalization of these potentials which would result in a charge being communicated to the connecting wire and the free quadrants. This again would set up a current to the surrounding tube $\mathbf{C}$, and finally the free 
quadranis would attain a steady potential, the current between the cylinders being equal to that between the connecting wire and its surrounding tube. The potential assumed by the free quadrauts under these circumstances, while approximating to, would be less than the contact difference of potential for the metals used in the two cylinders.

The values obtained in this way for any two given metals, while differing in sign, should be numerically the same whichever metal was used for the inner or outer cylinder. But on trial with a number of pairs of metals it was invariably found that the readings differed when an interchange was made of the metals in the cylinders. This is illustrated by the curves in fig, 3 , which give the results for the metals

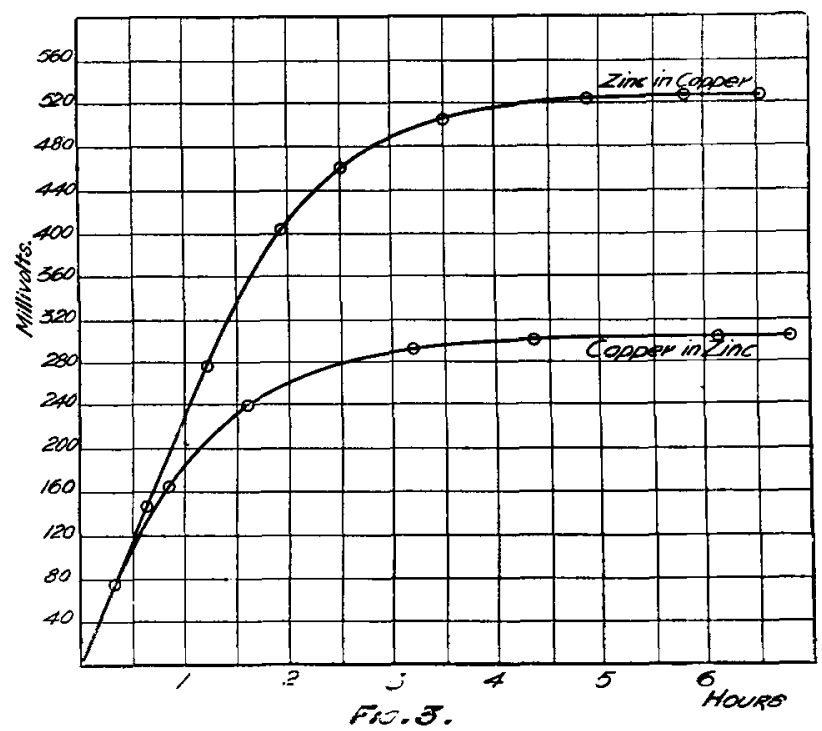

zinc and copper, the upper representing the negative potentials acquired by the quadrants with an inner cylinder of zine, and the lower the positive potentials with one of copper. The final potentials, it will be seen, are 527 and 304 millivolts respectively.

This result finds its explanation in the metal effect described above. We have shown that with zine cylinders the inner, in virtue of this effect, attains a potential of 160 millivolts below that of the outer, while with copper the corresponding value is 73 millivolts. If, then, we suppose the two "effects" to act concurrently, the final readings observed with the zinc and copper cylinders will represent their algebraic sum. 
Denoting the metal effect for zine by $x$ and that for copper by $y$, and the Volta effect for the two metals by V, we have

$$
\begin{gathered}
\begin{array}{c}
\text { Limiting Potential } \\
\text { (millivolts). }
\end{array} \\
\mathrm{V}+x=527, \\
\mathrm{~V}-y=304, \\
x=160, \\
y=73,
\end{gathered}
$$

from which we obtain the values 367 and 377 millivolts for the contact difference of potential for the metals zinc and copper, an agreement sufficiently close to confirm our hypothesis.

Similar measurements have been made with all combinations of the metals aluminium, zinc, lead, tin, and copper, taken in pairs, with uniformly close results, but the Volta effects obtained in this way were in every case proportionately less than the generally accepted values.

As an additional illustration of these measurements, the curves representing the results obtained with an inner cylinder of lead and an outer of each of the metals are

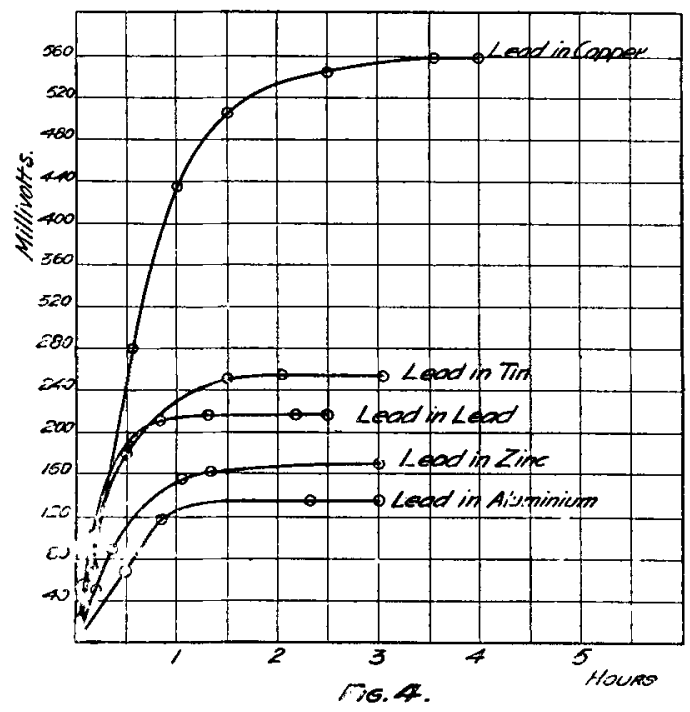

shown in fig. 4. Combining the limiting potentials of these with the metal effect for lead, 216 millivolts, the 
potential-differences for the different pairs of metals are as follows:-

\section{Difference of Potential.}

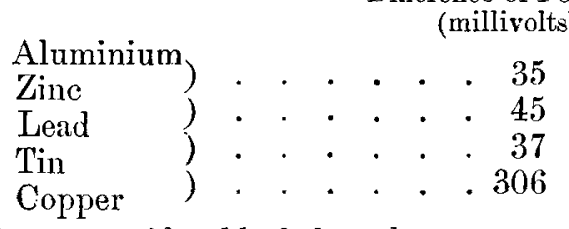

values which are considerably below those generally adopted.

\section{Conchusions.}

The gas between the two cylinders always contains a number of ions, and, on account of the greater rate of diffusion of the negative ions, it is possible that an excess of these would impinge upon the inner cylinder in a given time, and thus leave it negatively charged. The resulting potential, however, should be the same for all metals on this hypothesis.

Again, it is possible that the very penetrating radiation which is present in ordinary air may consist of negatively charged matter, and that the negative charge taken up by the inner cylinder represents the amount of this radiation intercepted by it. But the high value obtained for aluminium, together with the results obtained with Röntgen rays, is against this conclusion.

It seems rather that a process is going on at the surface of the metal, whereby an excess of positively charged corpuscles is being continually emitted, and that the steady state attained represents a condition of equilibrium in which the current between the cylinders is equal to the rate of efflux of the positive charges.

XLIII. A New Form of Platinum Resistance-Thermometer, specially adapted for the Continuous-flow Calorimeter. By H. T. Barnes, D.Sc., Assistant Professor of Physics, and D. MoIntosn, M.A., Demonstrator in Chemistry, Mc Gill University*.

NE of the difficulties to be overcome in constructing a sensitive platinum thermometer is to restrict the size of the coil of wire forming the bulb. In order to bave a sufficient length of wire it is often necessary to make the bulb inconveniently large, and thereby sacrifice quickness of register.

The form of thermometer which we have devised meets this difficulty to a considerable extent, and has enabled us to use shorter bulbs.

$$
\text { * Communicated by Prof. H. L. Callendar, F.R.S. }
$$

